\title{
FORMAÇÃO DE PROFESSORES DE ESPANHOL NO BRASIL E AS NOVAS(?) FORMAS DE ENSINO-APRENDIZAGEM À DISTÂNCIA
}

Ucy SOTO ${ }^{1}$

\author{
(pensando o virtual) \\ Existem outros mundos, \\ mas eles estão nesse. \\ Orwell \\ (pensando os computadores) \\ O homem cria as ferramentas, \\ as ferramentas recriam o homem. \\ McLuhan
}

\section{Resumo}

Tomando como ponto de partida o imaginário social (Hurtato Herrera, 2004) sobre língua espanhola, apresentamos uma discussão sobre a formação de professores de espanhol no Brasil e, especificamente, nos perguntamos o que muda e o que permanece no ato de ensinaraprender espanhol com a incorporação de TICs. Com base nos trabalhos de Dabène (1984) e de Carmagnani (2006), apresentamos uma análise - em fase inicial - de três diferentes formas/suportes para se trabalhar o ensino-aprendizagem de espanhol à distância, a saber: um cd-rom interativo, um curso on-line e uma plataforma de aprendizagem sem conteúdo prédefinido.

\section{Um desejo político claro e impasses não tão evidentes}

Para os que trabalhamos com língua espanhola no Brasil, o dia 5 de agosto de 2005 no qual o presidente da República, Luiz Inácio Lula da Silva, sancionou a Lei $\mathrm{n}^{\mathrm{o}} 11.161$, que torna obrigatória a oferta de língua espanhola nas escolas públicas e privadas de ensino médio em todo o país - é uma data memorável. Menos conhecido, no entanto, foi o que ocorreu no dia 5 de maio do mesmo ano: seguindo o mesmo espírito de abertura com relação ao mundo hispânico, realizou-se o lançamento dos protótipos dos passaportes brasileiros, dando-se destaque, entre eles, ao novo Passaporte Mercosul.

Por mais que possam parecer dois acontecimentos com pouca conexão entre si, os cotejaremos para dar início a nossa discussão sobre um dos impasses "invisíveis" que enfrenta a formação de professores luso-falantes brasileiros de língua espanhola. Uma primeira conclusão, óbvia, que se pode tirar dessas duas ações políticas - a lei e a criação de um passaporte Mercosul - é que ambas, claramente, visam a melhorar a integração entre os cidadãos dos países do Mercosul, no que diz respeito à comunicação lingüística (ensinoaprendizagem do espanhol por parte dos brasileiros) e ao trâmite aduaneiro (ir e vir de pessoas e, também, de mercadorias). No entanto, um grande impasse atravessa esse desejo, algo que por decreto ou por lei não se pode mudar: o imaginário brasileiro sobre a língua espanhola.

\footnotetext{
${ }^{1}$ (UNESP Araraquara) ucy@fclar.unesp.br
} 
No presente trabalho, antes de apresentar a análise de três formas diferentes para ensino-aprendizagem à distância, gostaríamos de tornar um pouco mais visível uma questão fundamental que afeta - de forma mais contundente do que possa parecer - a formação de docentes de língua espanhola no Brasil. Ao cotejarmos estes dois episódios, não o faremos como meros exemplos ilustrativos, mas como formas vivas de um imaginário social que devemos encarar e, principalmente, levar para o âmbito da formação tanto inicial como continuada de professores de espanhol.

A visão de língua(gem) entendida como discurso - e não como um sistema ou uma estrutura imanente - e o conceito sociológico de 'imaginário social' nortearão essa primeira parte de nosso trabalho. Compartilhamos o ponto de vista de Hurtado Herrera para quem os imaginários sociais

\begin{abstract}
se constituyen en singulares matrices de sentido existencial, como elementos coadyuvantes en la elaboración de sentidos subjetivos atribuidos al discurso, al pensamiento y a la acción social. Los imaginarios sociales siempre son contextualizados, ya que les es propia una historicidad caracterizante; no son la suma de imaginarios individuales: se requiere para que sean imaginarios sociales una suerte de reconocimiento colectivo, de tal manera que [para Castoriadis] "los imaginarios pasarían a ser sociales porque se producirían, en el marco de relaciones sociales, condiciones históricas y sociales favorables para que determinados imaginarios sean colectivizados, es decir instituidos socialmente." (Hurtado Herrera, 2004)
\end{abstract}

\title{
Um imaginário brasileiro sobre a língua espanhola
}

É comum afirmar-se que a comunicação é um dos grandes pilares da sociedade moderna. Um bom exemplo é o sem-número de emails que são enviados e recebidos diariamente - mas nem sempre lidos. Um desses emails que circulam livremente no novo território web da lusofonia é o que se reproduz a seguir.

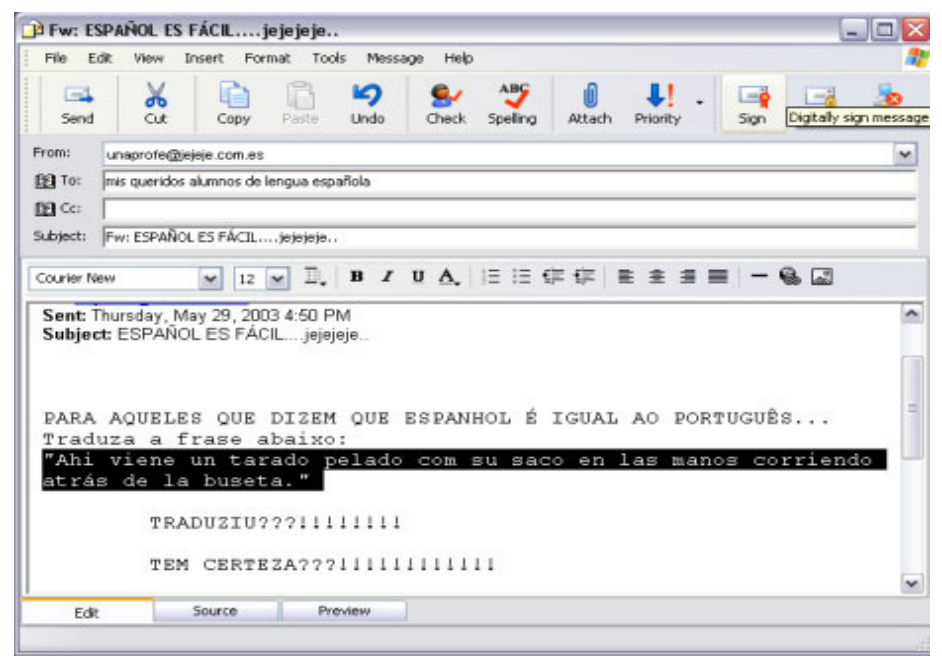

Logo em seguida é oferecida uma "Tradução: 'lá vem um tonto careca com seu paletó nas mãos correndo atrás do microônibus.' Pois é, além de não saber espanhol, só pensa besteira !!!!!!!!!!!!!!!”

A "besteira" é formulada por conta do famoso "portunhol" de domínio público no território nacional brasileiro. É o mesmo portunhol que está presente em muitos comerciais 
humorísticos de cursos de idiomas ou que faz parte de conversas de mesa de bar. Nada contra. $\mathrm{O}$ humor tem um lugar importante no discurso e na vida. Mas, o que pensar quando o portunhol - que de forma simplista reduz a diferença lingüístico-discursiva entre português e espanhol a uns poucos e famigerados falsos-amigos - rompe a barreira do território humorístico e do senso-comum privado e se lança também na redação de documentos oficiais de caráter eminentemente público?

Esse foi o caso encontrado no protótipo do passaporte Mercosul, divulgado com pompas e fitas no dia 5 de maio de 2005, poucos meses antes da promulgação da lei 11.161. Redigido até então em português, francês e inglês, o texto do passaporte que pede a autoridades estrangeiras ajuda e proteção aos portadores do documento incorporou a versão em espanhol.

"Em três linhas, consumou-se o naufrágio lingüístico", comenta Nunes (2005). Ao se deparar com o enunciado: "Ruegase a las autoridades de los paises extranjeros que presten toda ayuda e proteccion a lo titular de este pasaporte en caso de necessidad", qualquer aluno do primeiro ano de Licenciatura de um bom curso de Letras (habilitação: Espanhol) poderia detectar vários dos erros apontados como 'um naufrágio'. Mesmo um corretor automático reduziria significativamente seu número. O que aconteceu, então?

A explicação pela "incompetência" seria demasiadamente reducionista e simplista. Mais preocupante que os erros em si mesmos é o fato de se tratarem de problemas lingüísticos tão primários que só podem ser interpretados à luz de um quadro mais amplo, onde se leve em conta o lugar "singular" que o espanhol ocupa como língua estrangeira no Brasil. Este é um lugar marcado pela indeterminação entre ser ou não - considerado como - uma língua estrangeira. "Espanhol, todo mundo sabe, não precisa nem estudar!", ouve-se repetidamente. González (2004) nos fala da dificuldade de estabelecermos "la medida de una justa cercania" entre português e espanhol no Brasil. Nesse não-lugar reservado à língua espanhola no nosso imaginário social, acreditamos encontrar uma das chaves para responder à questão formulada acima.

Celada e Rodrigues (2005) destacam as características desse imaginário, que tem dois momentos diferenciados. Contraditoriamente - dizem as autoras - desse imaginário fazem parte, num primeiro momento "la ilusión de competencia espontanea", o efeito de transparência e a imagem de facilidade. E, num segundo momento, essa imagem inicial se estilhaça e se passa a uma segunda imagem, marcada por uma idéia de que "el español es difícil, correcto, detallista redundante, complicado, rebuscado, formal, mandón".

Esta ilusão de competência espontânea, este efeito de transparência e a imagem de facilidade inicial nos ajudam a compreender como funciona esse imaginário. O protótipo de um passaporte, adjetivado de mercosul, redigido em portunhol por uma das instituições oficiais do Estado é extremamente revelador. Deixa claro que esse imaginário se estende não só ao âmbito privado, do humor ou das propagandas, mas que atravessa um variado espectro de atividades sociais indiscriminadamente, inclusive as oficiais. Celada e Rodrigues (2005, p.3) destacam ainda que o que primou na relação do brasileiro com a língua espanhola foi o fato de que, historicamente, no horizonte das línguas estrangeiras, ela não chegou a ocupar um "lugar". Concordamos com as autoras quando afirmam que o espanhol foi, durante muito tempo, uma língua que não chegou a ser considerada objeto de um suposto saber pelo qual valesse a pena o trabalho de se submeter ao seu estudo. 
Apesar dos pesares, nos últimos anos, a relação lingüístico-discursiva entre os falantes do português e espanhol se viu submetida a certas mudanças. No âmbito acadêmico brasileiro, cresceu significativamente o número de estudos de pós-graduação, stricto e lato sensu, que tomam o espanhol como "objeto de estudo", sob os mais diversos olhares teóricos e aplicados (Soto, 2004). Este trabalho vem produzindo seus resultados. Um deles é a introdução de novos questionamentos lingüístico-discursivos na formação de profissionais da área de Letras no contexto brasileiro. Novos profissionais que, por formação, estão mais preparados para trabalhar não só habilidades lingüísticas mas, principalmente, posicionar-se quanto ao lugar das línguas - estrangeira e materna - num quadro mais amplo que vê a educação como o espaço de formação de cidadão críticos. Este, parece-nos, é o papel fundamental da formação de professores: (re)trabalhar conteúdos e representações imaginárias para, quem sabe, produzir "en un determinado momento una ruptura de las significaciones imaginarias para dar lugar a lo nuevo". (Franco, 2003)

\section{Novas (?) formas de ensinar-aprender espanhol usando TICs}

A seguinte pergunta poderia resumir esta segunda parte de nosso trabalho: O que muda e o que permanece no ato de ensinar-aprender espanhol com a incorporação de TICs? Tomando como base os trabalhos de Dabène (1984) - que descreve as operações metacomunicativas na sala de aula de línguas estrangeiras - e de Carmagnani (2006) - que se ocupa do impacto das novas tecnologias nos sujeitos e no discurso -, apresentaremos uma análise, ainda em fase inicial, de três diferentes formas/suportes para se trabalhar o ensinoaprendizagem de espanhol à distância.

Após a pré-seleção entre uma gama de materiais, decidimos pela análise de três diferentes formas um CD-Rom interativo, um curso on line e uma plataforma de aprendizagem, numa metodologia de estudo de caso. Os materiais selecionados foram considerados prototípicos de sua categoria e apresentam uma qualidade técnica acima da média. O curso em CD-Rom interativo analisado foi o Aprenda a hablar español da Ed. Planeta, o curso on line foi o Aula Virtual de Español (modalidade com tutor responsável por um grupo de estudantes) do Instituto Cervantes e a plataforma sem conteúdo pré-definido foi a Moodle, uma plataforma virtual de aprendizagem de código aberto, livre e gratuita criada por Martin Dougiamas.

Concordamos com Carmagnani quando afirma que

o "novo" não reside necessariamente no material propriamente dito, mas naquilo que este possibilita em termos das relações estabelecidas entre os interlocutores e destes com o mundo virtual apresentado na tela, oferecendo outras alternativas de experiência pedagógica." (Carmagnani, 2006, p. 167)

Assim sendo, visamos tornar visível que tipo de relações se estabelecem entre os envolvidos na experiência pedagógica em cada uma das diferentes formas ensinar-aprender espanhol selecionadas. Nosso objetivo é cotejar as diferenças e similaridades que existem entre elas. Para isso, apresentamos, em primeiro lugar, uma breve descrição do material e, em seguida, os resultados da análise que busca dar a conhecer as diferentes possibilidades quanto a: a forma como se dá a interação, a língua usada para comunicação e a variedade de espanhol apresentada, as atividades propostas, a questão do tempo, os conteúdos, o processo avaliativo.

Um curso de espanhol em CD-Rom interativo 
Aprenda a hablar español é um curso de língua espanhola desenvolvido em oito CD-ROMs, os quais se apresentam como trazendo "situações reais enfrentadas no cotidiano ou em viagens ao exterior". Através das lições descritas como "práticas", o curso se propõe a "aperfeiçoar a pronúncia do aluno (gravando a sua própria voz), aprender gramática e compreensão de texto".

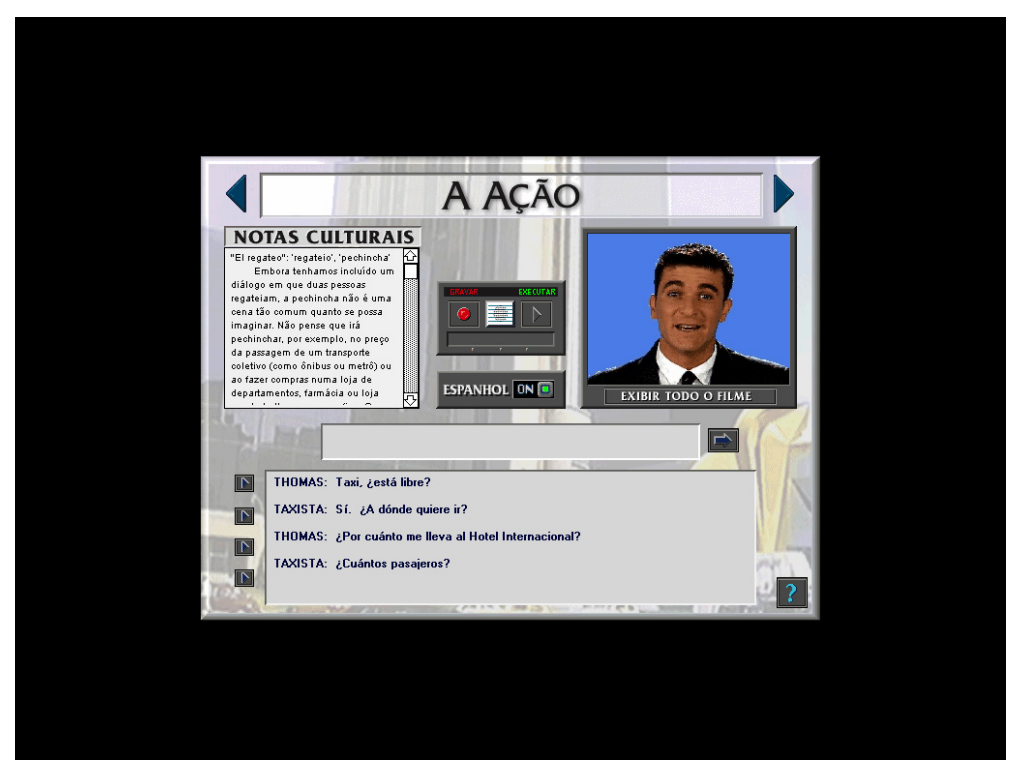

Tela com atividade de diálogo do CD-Rom

A interação se dá off line entre o estudante e o programa computacional que simula um contato direto e amigável com o usuário quase que exclusivamente por escrito. $\mathrm{O}$ ato de clicar funciona como a grande metáfora para o processo interativo.

A língua de comunicação é quase que exclusivamente o português e a variedade de espanhol apresentada é majoritariamente a mexicana.

As atividades propostas são majoritariamente exercícios tipo drills, às vezes mais, às vezes menos sofisticados, nas modalidades escrita e oral. Existe ainda a possibilidade de oralização de frases que podem ser gravadas e submetidas a correção.

O tempo é tido como sob controle por parte do estudante. O estudante acredita ter sob seu controle sua aprendizagem e tem a sensação de que o 'seu interlocutor' está sempre disponível.

O conteúdo vem pré-estabelecido e simula uma viagem ao México (partindo dos Estados Unidos?!). Não há qualquer possibilidade de negociação, substituição ou acréscimo no que foi estabelecido.

O processo avaliativo é levado a cabo pelo programa e o estudante tem que realizar os exercícios exatamente como está previsto no programa, caso contrário, as respostas são consideradas como erro. Não há qualquer possibilidade de negociação.

Curso de língua espanhola on-line (modalidade com tutor e turma) 


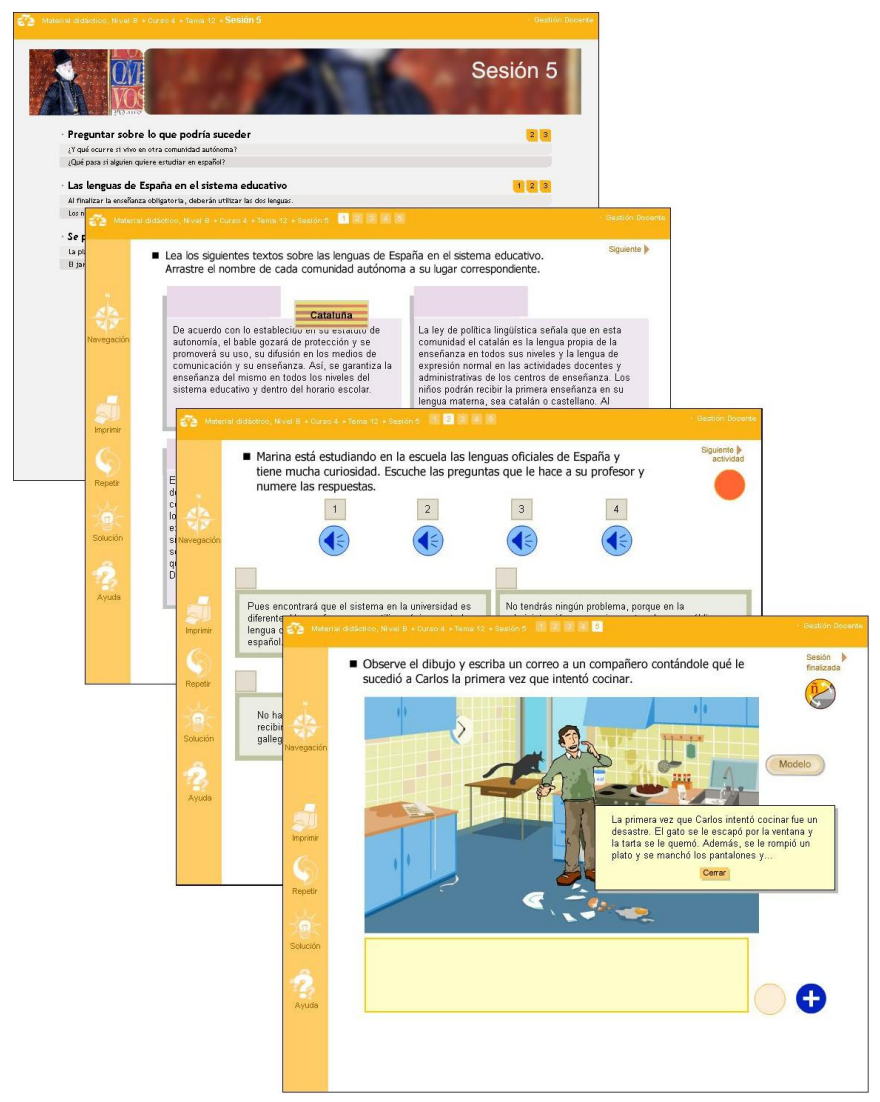

A Aula virtual de español (AVE), do Instituto Cervantes, é uma ambiente didático que oferece cursos para aprendizagem de espanhol via Internet. São oferecidos quatro níveis de cursos inicial, intermediário, avançado e superior. Os níveis estão organizados em cursos e estes em temas. O curso apresenta como objetivos fazer com que o aluno aprenda "a desenvolverse adecuadamente en español en diferentes situaciones", estude "todos los aspectos: gramática, lécico, fonética, ortografía..." e que conheça "la realidad sociocultural del mundo de habla hispana". O projeto recebeu o patrocínio do Ministerio de Industria, Turismo y comercio, do Banco Santander, Microsoft e Telefônica.

Telas superpostas de algumas atividades do A.V.E.

A interação se dá sempre on line entre o estudante e o programa; o estudante também pode interagir com outro/s estudante/s, além de com o tutor [que tem uma função diferente da do professor, cf. Belo (2006)]

A língua de comunicação é prioritariamente o espanhol, mas há certa possibilidade de negociação por parte do estudante. $\mathrm{O}$ tutor deve comunicar-se com o grupo exclusivamente em espanhol.

No que diz respeito às atividades propostas, encontramos atividades parecidas às do CD-Rom interativo, porém com um design muito mais atrativo e com a possibilidade de certa liberdade nas respostas abertas. Existem atividades, principalmente nos níveis mais avançados, de produção textual corrigida pelo tutor e uma série de ferramentas sofisticadas são disponibilizadas, tais como: chats, fóruns e emails que permitem vários níveis de interação entre os interlocutores. Há também uma variedade de hipertextos pedagógicos e a possibilidade de consulta à web. O curso está instalado em uma plataforma de aprendizagem que integra todas as atividades e ferramentas.

Na modalidade escolhida para análise, o tempo é o tempo de duração do curso, aproximadamente um semestre por módulo. Existem outras modalidades de utilização do curso, por exemplo, sem tutor, na qual o tempo pode ser mais "elástico", mas a possibilidade de interação se reduz drasticamente.

O conteúdo, como no CD-Rom, também é pré-estabelecido, mas há a possibilidade de aporte por parte do tutor a modo de complementação, esclarecimentos ou atividades extras. 
A avaliação é realizada basicamente pelo programa, com auxílio do tutor para a correção das atividades abertas, tais como a produção de textos em níveis avançados.

\section{Plataforma de aprendizagem sem conteúdo pré-estabelecido}

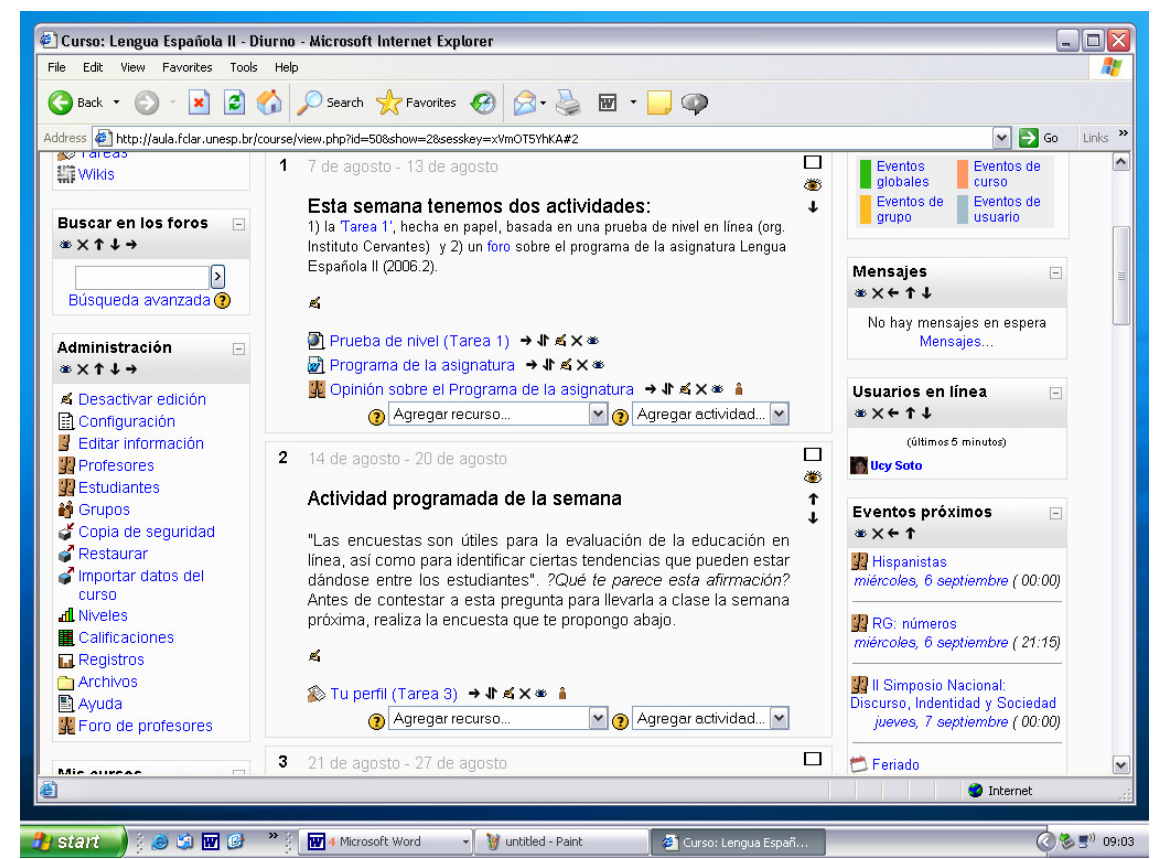

Tela do professor na sala virtual de "Lengua Española II" no Moodle, Unesp Araraquara

Como no curso on line anteriormente apresentado, há uma variedade de possibilidades de interação entre os vários interlocutores. Aqui, além da interação entre estudante/s, professor/es e/ou tutor/es do curso, interage-se também com as ferramentas e atividades da plataforma. Além desses interlocutores, um estudante que trabalhe nesta plataforma entra para comunidade na qual o curso está integrado. Por exemplo, um estudante de "Lengua Española II" faz parte, automaticamente, da comunidade Moodle em que está inserido, podendo fazer contato, ser contatado por outros usuários da plataforma da Universidade Estadual Paulista, Campus Araraquara, na qual se encontra sua disciplina, além de poder acessar os conteúdos abertos de outras disciplinas/portais.

A língua de comunicação é definida pelo professor e a plataforma disponibiliza todo interface em espanhol se assim o deseja o professor.

As atividades devem ser criadas pelo professor. Podem incluir as mencionadas para o CD e para o curso on-line dependendo do conhecimento de programas por parte do professor ou de sua equipe. Há a possibilidade de enlaces de páginas da web.

O tempo também é definido pelo professor segundo suas necessidades e a organização do seu curso. Pode durar um semestre, um ano ou ficar em aberto.

Não há conteúdo pré-definido. Todo o curso tem que ser criado pelo professor. Uma grande vantagem é a possibilidade de se reaproveitar o material já criado para um novo curso. E também a possibilidade de se "arquivar" o resultado do trabalho com os alunos. 
A avaliação fica a critério do professor, não há nada na plataforma que a defina.

Existe a possibilidade de criação, publicação e circulação de material realizado não só pelo professor como pelos estudantes.

Falar sobre o impacto das TICs nas práticas docente e discente é um tema ao mesmo tempo desafiador e complexo. Com certeza as novas tecnologias promovem mudanças nas relações estabelecidas no modelo presencial de ensino-aprendizagem. Voltando ao começo de nossas inquietações, voltando à questão de formação de professores, nos perguntamos: até que ponto os conteúdos pré-estabelecidos de um programa podem realizar parte das funções que inicialmente era reservada somente ao professor: a de avaliar, por exemplo? Como fica a questão da negociação? Ser professor de língua, em nosso caso espanhola, exige bem mais do que saber linguiístico. Nenhum programa à distância disponível no Brasil - pelo menos no presente momento - trabalha com essa dimensão formativa e reflexiva do professor. As ferramentas e as atividades que se realizam on-line podem, em muito, ajudar na formação de professores, mas essa formação, insistimos, não pode se limitar a aprender "a língua" (essa unidade inexistente) e sim refletir e posicionar-se quanto ao lugar das línguas - estrangeira e materna - num quadro mais amplo que vê a educação como um espaço para formação de cidadão críticos.

\section{REFERÊNCIAS CONSULTADAS E MATERIAL ANALISADO}

Aprenda a hablar español”- Curso interativo. 8 CD-Roms Ed. Planeta, distribuído pela Folha de São Paulo no ano 1998 junto com o Jornal Folha de SP.

Aula Virtual de Español (A.V.E.) Instituto Cervantes - http://ave.cervantes.es/

BELO, Wagner Rodrigues (2006) Novas relações virtuais? Um estudo de caso da interação tutor-aluno no ambiente AVE (Aula Virtual de Español). Dissertação de Mestrado em Letras, Universidade Federal Fluminense.

CARMAGNANI, Anna Maria G. (2006) Impacto das novas tecnologias nas identidades : o caso de cursos de línguas online. In: MAGALHÃES, Izabel, GRIGOLETTO, Marisa e CORACINI, Maria José (orgs.) Práticas identitárias: Língua e discurso. São Carlos: Editora Claraluz.

CELADA, Maria Teresa y RODRIGUES, Fernanda dos Santos Castelano. El español en Brasil: actualidad y memoria. Real Instituto Elcano de estudios internacionales y estratégicos

http://www.lai.at/wissenschaft/lehrgang/semester/ss2005/rv/files/celadayrodrigues.2005 .pdf capturado em 12/12/2005

DABÈNE, Louise. (1984) Pour une taxinomie des operations métacommunicative en classe de langue étrangère. In. Ètudes de linguistique appliqué, 55.

FRANCO, Yago. http://www.magma-net.com.ar/xiros.htm capturado em 2/6/2006 
GONZÁLEZ, Neide Maia. Lugares de reflexión en la formación del profesor de E/LE (La particular situación de Brasil) Revista RedELE, março 2004 http://www.sgci.mec.es/redele/revista/neide_gonzalez.shtml capurado em 23/4/2005

HURTADO HERRERA, Deibar René. Reflexiones sobre la Teoría de Imaginarios. Una posibilidad de comprensión desde lo instituido y la imaginación radical. http://www.moebio.uchile.cl/21/hurtado.htm capturado em 9/4/2006

LORENZONI, Ionice. Espanhol será obrigatório no ensino médio. http://www.lainsignia.org/2005/agosto/ibe_022.htm capturado em 27/11/2005

Moodle (Modular Object Oriented Dynamic Learning Enviroment) http://moodle.org/sites/

NUNES, Augusto. (2005) Passaporte para o portunhol. Jornal do Brasil, 15/5/2005

SOTO, Ucy. (2004) Stricto Sensu: regularidades e dispersão na pesquisa em língua espanhola. In: TROUCHE, André e PARAQUETT, Marcia (orgs.) Formas \& Linguagens: Tecendo o Hispanismo no Brasil. Rio de Janeiro: CCLS Publishing House. 